\title{
A new approach to urban transshipment problem using electrical trucks
}

\author{
Yavuz GÜNALAY, Levent AKSOY2, and Burak KÜÇÜK3
}

\begin{abstract}
As the urbanization rate increases every day, city logistics become more and more important. Electric vehicles are both environmentally friendly and also less costly alternative to internal combustion engine vehicles. However, decision methods employed by businesses are not useful to evaluate these systems. We propose a new model that helps businesses to evaluate the contribution of electric vehicles in city logistics.
\end{abstract}

Keywords- urban logistics, electric vehicles, transshipment problem

\section{Introduction}

Freight transport within the cities plays an important role for sustainable development of cities. However city transportation face problems originated from traffic congestion, high fuel usage, lack of human resources and environmental factors. Even under these tight conditions, the carriers are expected to provide low cost justin-time transportation systems with high levels of customer satisfaction. To address these problems a new field, called urban logistics, has emerged.

The concept of urban logistics tries to optimize logistics activities within the cities under social, environmental, energy, economic and financial constraints.

Urban logistics (city logistics, urban freight transport) is the optimization of logistics and transportation activities in urban areas taking environmental, traffic congestion and energy usage into consideration and within market economy framework [1].

The reason urban logistics became a separate field is due to properties of the cities. All logistics activities take place within the many constraints of the cities. Planning in addition to economic returns, urban planning should target sustainability addressing social and environmental issues. Without a logistics plan, city planning will not be able to improve quality of life - thus making urban logistics one of the basic components of urban planning [2]

Yavuz Gunalay

Bahcesehir University

Turkey

Levent Aksoy

Konya Food \& Agriculture University

Turkey

Burak Kucuk

Maltepe University

Turkey
Street level emissions and noise pollution are two of the major problems facing urban logistics. Replacing internal combustion engine with silent running zero emission electric motors is one way to overcome such issues.

\section{Urban Logistics}

The emissions of noxious and greenhouse gases per unit of work done have been reduced. On the roads this is measured in terms of amount of emissions (usually grams) per $\mathrm{km}$ for small and light duty vehicles, amount of emissions per ton per $\mathrm{km}$ for heavy duty vehicles and cargo transport. Although there has been a significant decrease in vehicle emissions due to tight measures by governments (both in the US and EU), total emissions in the EU have increased due to increased traffic [3].

The air quality may have increased on the highways; but it is still a major problem on urban roads. Further measures should be taken in order to reduce the effects on human health.

Noise pollution is a major cost of transportation. It has been estimated that $8 \%$ of external costs is noise in the EU [4]. Heavy trucks and buses, diesel engine cars and motorcycles all contribute to the noise levels.

The advances in battery technologies in recent years revived the use of electric vehicles. These vehicles using high efficiency electric motors have advantages such as low fuel and maintenance costs, zero emissions (thus improving urban air quality as well as decreasing total carbon emissions) and silent operations. This new technology still lacks widespread use due to low range, long recharge times and high initial costs.

\section{Electric vehicle selection problem}

Recent advances in automotive and electric storage technologies make electric vehicles to be looked upon. There still appears to be a long way even to consider EV's as an option for long range transportation. Their range and recharging times make EVs either operationally not feasible or prohibitively expensive. However their low cost of operation has made electric vehicles the new kid in the block - an alternative to the internal combustion engine (ICE) models in city transportation.

The decision to acquire and integrate a new technology requires good technology management, operations management and decision making skills. Optimization is one of the main tools in decision making; one tries to find the best solution among the feasible solutions. Of course we mean feasibility from technical, operational, economic, legal and scheduling perspective, while the perspective should be objective and unbiased. 
Economic analyses usually apply a cost-benefit perspective in which a solution is feasible if benefits outweigh the costs. If there are uncertainties involved probabilistic methods, such as the expected value, might be used. For complex problems where it is hard to measure numerical values, we might assign subjective values as in Point Factor Analysis and AHP.

If we approach the problem of selecting an engine type (electric vs. ICE) via a comparative decision making, it wouldn't be hard to see why we still use combustion engine vehicles and simply not convert to EVs.

Table 1 shows the basic criteria used to compare EVs and ICE vehicles, and approximate values for ICE and EV.

Table 1. Comparison of Internal Combustion Engine and Electric Vehicles

\begin{tabular}{|c|c|c|}
\hline Criteria & ICE & $\mathrm{EV}$ \\
\hline $\begin{array}{l}\text { Fixed } \quad \text { (purchasing) } \\
\text { cost }^{1}\end{array}$ & 100 units & $120-200$ units \\
\hline Maintenance costs ${ }^{2}$ & 100 units & $30-50$ units \\
\hline Fuel costs ${ }^{3}$ & 100 units & $15-40$ units \\
\hline $\begin{array}{l}\text { Environmental } \\
\text { impact }^{4}\end{array}$ & High & Low \\
\hline Range $^{5}$ & $800-1000 \mathrm{~km}$ & $100-200 \mathrm{~km}$ \\
\hline $\begin{array}{l}\text { Refueling } \\
\text { (recharging) times }\end{array}$ & $5-15 \min$ & 1-6 hrs. \\
\hline
\end{tabular}

(Note: The figures shown use "units" to depict the ratio of the costs.)

\footnotetext{
${ }^{1}$ Upper limit based on 2013-2014 Ford Focus, Nissan Leaf, Nissan Versa, Honda Fit, Toyota RAV4 pricing (motortrend.com). Lower limit is based on expected costs of batteries@300 USD/KWh (alibaba.com).

${ }^{2}$ Estimate based on lubricant oil use and maintenance. Electric motors have very low cost of operation; EVs have battery maintenance instead. New batteries can be recharged up to 5,000-10,000 times - roughly the life of the vehicle.

${ }^{3}$ Costs are based on EV's being $50-70 \%$ efficient, and electricity pricing scheme in Turkey (tedas.com.tr).

${ }^{4}$ Environmental impacts of diesel engines include high carbon emissions and particle emissions at street level. Even if electricity is generated from fossil fuels, the emissions are much lower.

${ }^{5}$ Range depends on the size of the batteries. For useful operations, minimum range needs to be $100-200 \mathrm{~km}$.

${ }^{6}$ Smart phones and other electronic devices using the same Li-ion technology can fully recharge batteries in about two hours, to $80 \%$ capacity in about an hour. Provided sufficient power and cooling, car batteries should have similar charging times.
}

A typical EV will add to the cost of the vehicle by $20 \%$ to $50 \%$ based on the configuration. The cost increase mostly comes from the cost of Lithium-ion batteries although other parts especially the engine is costlier than an electric motor. The maintenance costs of EVs are half to a third of combustion engines as there is only a one rotating part in an electric motor as opposed to many moving parts in a combustion engine. Of course fuel costs are very favorable for EVs. Depending on the petrol and electricity prices, cost per km (mile) is at least half ( $\left.\mathrm{USA}^{7}\right)$ to one-sixth (Turkey). Environmental impact of EVs depends on how electricity is generated. From carbon emissions point of view there is still an improvement even when electricity is generated from a coal fired plant. From the point of view from air quality at street level EVs are no match for the exhaust of a diesel truck.

The current battery technologies still cannot match the versatility of petrol. One can refuel the vehicle in 5 minutes and drive more than $500 \mathrm{~km}$. EVs on the other hand require at least an hour to recharge its batteries only to provide a $100-200 \mathrm{~km}$ range. Swapping the battery or replenishing the electrolyte fluid are two alternatives to quick charging, however, range limitation still applies.

For long range transportation recharging points may be planned alongside with driver rest periods. European Commission limits the longest continuous driving time to $4.5 \mathrm{hrs}$. with $45 \mathrm{~min}$ rest period. Thus a vehicle needs to have approximately $300-400 \mathrm{~km}$ range and be charged in less than an hour. To complete a journey, travel and rest times nust be synchronized with battery charging requires quite a technical challenge.

For city logistics range is less of a problem than the cost of the battery to provide the required range. There's plenty of recharging periods such as loading/unloading or the night time. Still, for a city like Istanbul, where $100 \mathrm{~km}$ plus routes are quite common, the range (typically 100-150 $\mathrm{km}$ ) puts operational limitations. Refrigeration equipment put extra load on the batteries as well (which reduces the range).

If one states the vehicle selection problem as the simple choice between an EV and an ICE, the decision will most likely to be in favor of a petrol engine. The proof is that the sales of EVs being marginal.

However we could end up with a different solution if we stated the problem as finding the optimal proportion of EVs in a fleet to minimize the cost. For the sake of simplicity we will compare operational costs; however comparison should be made according to the total cost (including environmental costs).

\section{Transshipment problem with capacitated vechicles}

Let's assume we have an urban distribution network consisting of a warehouse (A) and four stores (B, C, $\mathrm{D}$, and E) (Figure 1). Let us also assume the demand at each

${ }^{7}$ Based on EPA ratings, savings are at least $50 \%$ when compared with hybrids, more when compared with petrol engines. 
store is 1 unit/day and is delivered daily by a truck with 2 unit capacity. Let transportation costs be proportional to the distance covered and independent of the amount of load. Minimum cost is achieved by making two separate rounds, $A-B-C-A$ and $A-D-E-A$, and is equal to 240 units. $^{8}$

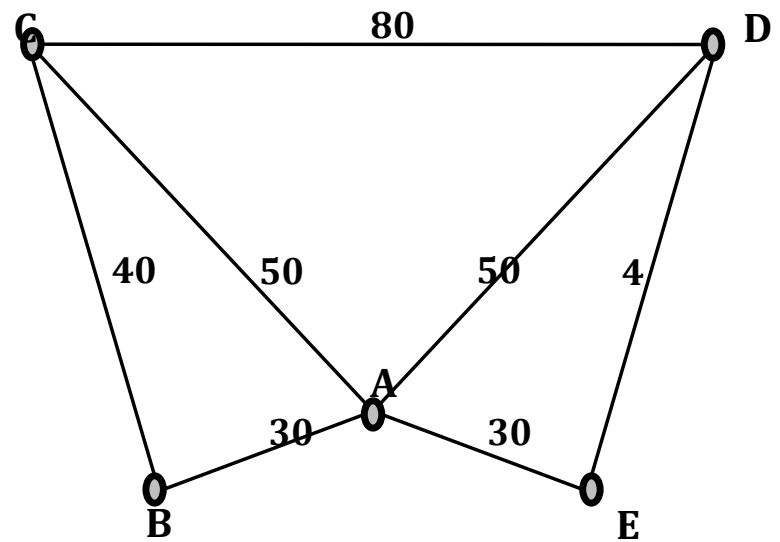

Figure 1 Sample Distribution Network

(Numbers denote the distance/cost between nodes)

If we could replace the whole fleet with electric vehicles (with $1 / 6$ fuels costs) the total costs will be 240 / 6 $=40$ units. However if a typical, reasonable cost electric truck has a $100 \mathrm{~km}$ range, then it would operationally not be feasible to make $120 \mathrm{~km}(50+40+30)$ runs, or even reach nodes $\mathrm{C}$ or $\mathrm{D}$. If the problem were stated as whether to replace combustion engines with electric vehicles the answer would most likely be 'NO' for feasibility reasons.

Instead we could state the problem as 'the ratio of the fleet to be converted to EVs' then we would have a different answer. That is "what routes might be covered with EVs and what routes still require combustion and have lower total cost?"

In the sample network if nodes $\mathrm{B}$ and $\mathrm{E}$ were served by EVs, while $\mathrm{C}$ and $\mathrm{D}$ still but combustion vehicles, optimal routes $A-C-D-A$ and $A-B-A-E-A$ will have a total cost of 200 units $(180+120 / 6)$. This is a better value than the original 230 units.

\section{Range Limited Routing Problem}

Besides the fleet renewal problem, we also face the fleet routing problem due to the short range of electrical trucks. For a detailed analysis of vehicle routing problem (VRP) see the recent review by Kumar and Pannerselvam (2012). Toth and Vigo also reviewed capacitated vehicle routing problems (CVRP) in their 2002 article. Our problem represents a new challenge due to the range limitations of electrical trucks. The following model optimizes the routing problem under the range constraint, which we call Limited Range Capacitated Fleet Routing Problem (LRCFRP).

\section{Notation:}

$\mathrm{k}$ - index for trucks $\mathrm{k}=1, . ., \mathrm{K}$.

$\mathrm{i}, \mathrm{j}$ - index for node (stores: $1, \ldots, \mathrm{N}$ and warehouse: 0 ).

${ }^{8}$ The routes $A-B-A-E-A$ and $A-C-D-A$ have a total cost of 280 units; the routes $A-B-A-D-A$ and $A-E-A-C-A$ have a total cost of 300 units.
$\mathrm{R}_{\mathrm{k}}$ and $\mathrm{T}_{\mathrm{k}}-$ represents truck range and capacity, respectively, $\mathrm{k}=1, \ldots, \mathrm{K}$.

D0 - warehouse capacity.

$\mathrm{d}_{\mathrm{i}}-$ demand at node $\mathrm{i}, \mathrm{i}=1 . ., \mathrm{N}$.

$\mathrm{r}_{\mathrm{ij}}$ - distance between node $\mathrm{i}$ and $\mathrm{j}, \mathrm{i}, \mathrm{j}=0, . ., \mathrm{N}$.

$1_{\mathrm{ik}}$ - load transshipped to node $\mathrm{i}$ using truck $\mathrm{k}$.

The assumption is that total capacity is equal to total demand and there is no excess capacity:

$$
\sum_{k=1}^{K} T_{k}=\sum_{k=1}^{N} d_{i}
$$

Then, the model

Max

$$
\sum_{k=1}^{K} \sum_{i=0}^{N} \sum_{j=i+1}^{N} d_{j} x_{i j k}
$$

s.t.

$$
\begin{aligned}
& \sum_{k=1}^{K} \sum_{j=1}^{N} x_{0 j k} \leq K \\
& \sum_{\substack{i=0 \\
i \neq j}}^{\mathbb{N}} x_{i j k}=\sum_{\substack{i=0 \\
i \neq j}}^{\mathbb{N}} x_{j=j} \quad \forall j, k
\end{aligned}
$$

$\sum_{\substack{j=1 \\ j \neq i}}^{\mathbb{N}} x_{i j k} \leq 1 \quad \forall k_{x} i$

$\sum_{\substack{i=1 \\ i \neq j}}^{\mathbb{N}} x_{i j k} \leq 1 \quad \forall k_{i} j$

$$
\sum_{i=0}^{\mathbb{N}} \sum_{\substack{j=0 \\ j \neq i}}^{\mathbb{N}} r_{i=1} x_{i j k} \leq R_{k} \forall k
$$

$$
l_{j k} \leq d_{j} \sum_{\substack{i=0 \\ i \neq j}}^{\mathbb{N}} x_{i j k} \quad \forall j, k
$$

$\sum_{k=1}^{K} l_{i k} \leq d_{i} \quad \forall i$

$\sum_{i=1}^{N} l_{i k} \leq T_{k} \quad \forall k$ 
The model assures that at most $\mathrm{K}$ trucks are used to deliver the goods (eqn 3 ), trucks route are continuous and nonrecurrent (eqn. 4-6), trucks do not travel beyond their range (eqn. 7), demand at each store is satisfied by at least one truck (eqn 8-10). For a feasible that maximizes the satisfied demand at each node is the optimum truck routing solution for our problem. This way we can search for the feasibility of the electrical fleet for the urban transportation problem. Along with the break even analysis given in section IV, the firm could make an urban cargo fleet forming decision.

\section{Concluding Remarks}

Electric vehicles may fall short of the requirements of long-haul heavy-truck transportation but there's room for using them in urban logistics. The decision to use electric vehicles can be made either through a one-on-one comparison of two types of vehicles and choosing one type, or, the ratio of partial electrification of routes. Although EVs may not look feasible in general, some of the routes, when electrified, may offer further cost reduction. Firms need to explore the routes suitable for electrification to lower their costs. The LRCFRP model presented solves the problem but quite challenging in terms of computational resources. Therefore an efficient solution heuristic for this model is still in search.

\section{References}

[1] Taniguchi, E., Thompson, R.G., Yamada, T., van Duin, R. (2001), City Logistics, Pergamon, Holland, p.9

[2] Eiichi Taniguchi, Bob E. C. M. van der Heijden, "An Evaluation Methodology for City Logistics", Transport Reviews, Vol 20, 2000, s. 65.

[3] Ten key transport and environment issues for policymakers, EEA Report, No. 3/2004, European Environment Agency, Copenhagen, 2004.

[4] http://ec.europa.eu/clima/policies/transport/vehicles/ind ex_en.htm

[5] Otomativ Teknoloji Platformu (OTEP) - ( Automotive Technology Platform), 2010, "Elektrikli Araç Çalışma Grubu Raporu".

[6] Tuncay R. N., Üstün Ö., 2012, “Otomativ Sektör Kurulu Raporu: Elektrikli Araçlarda Geçmişten Geleceğe Bakış", MÜSİAD.

[7] Brouwer A. S., Kuramochi T., Broek M., Faaij A., 2013, "Fulfilling the Electricity Demand of Electric Vehicles in the Long Term Future: An Evaluation of Centralized and Decentralized Power Supply Systems", Applied Energy 107 (2013) 33-51.

[8] Richardson D. B., 2012, "Electric Vehicles and the Electric Grid: A Review of Modeling Approaches, Impacts, and Renewable Energy Integration", Renewable and Sustainable Energy Reviews 19 (2013) 247-254.

[9] Weiss M., Patel M. K., Junginger M., Perujo A., Bonnel P., Grootveld G., 2012, "On the Electrification of Road Transport - Learning Rates and Hybrid-Electric and Battery Electric Vehicles", Energy Policy 48 (2012) 374-393.

[10] Commercial Development of Regional Ports as Logistics Centres editor: United Nations. Economic and Social Commission for Asia and the Pacific (ESCAP) 2003.

[11] Eurostat European Commission, 2009, "Panorama of Transport".

\section{About Authors:}

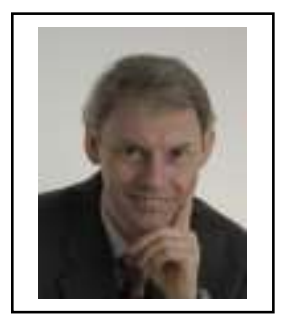

Yavuz Gunalay is a Professor at Bahcesehir University, and the Chair of Logistics Management Department. He earned his B.S. and M.S. from METU and Bilkent University in Turkey and then got his Ph.D. from McMaster University, Ontario. He has worked at Eastern Mediterranean University and Bilkent University before joining Bahcesehir University. His research interests include disaster logistics, stochastic modeling of manufacturing, remanufacturing and telecom systems.

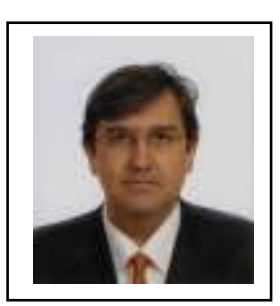

Levent Aksoy is an Assistant Professor at Konya Food and Agriculture University, the Chair of Economics Department and the Manager for Continuing Education. He earned his B.Sc. in Electrical Engineering from Bosphorus University, Turkey, and Ph.D in Economics from City University of New York. $\mathrm{He}$ worked at various CUNY colleges and Maltepe University. His research interests include electric vehicles and disaster logistics.

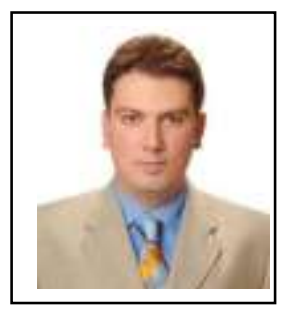

Burak Kucuk is an Assistant Professor at Maltepe University. He earned his BA from Ataturk University, MA degree from Yeditepe University and Ph.D. from Maltepe University. $\mathrm{He}$ has been working at Maltepe University International Trade and Logistics Management Department. His research interests include regional development and disaster logistics. 